\title{
THE COST OF ONCOLOGY MEDICINES
}

\author{
A. Zlatareva, K. Krahtova and Tch. Kazak \\ Medical University - Varna
}

\begin{abstract}
Cancer as a financial value is one of the most expensive diseases. Costs, including the cost of new cancer drugs, are increasing at an unsustainable rate, threatening the permanent access of patients to treatment. Prices for new treatments against cancer have doubled over the past 10 years and now are usually between USD 6000 and USD 10,000 per month, this increase is often not correlated with reimbursement and implemented public health benefits. According to various authors, these results lead to debate whether the cost differences between EU countries and the US for the treatment of oncologic diseases are transformed into improved outcomes for patients, and must also take into account key factors such as lifestyle, late diagnosis, and management approach for treatment, reimbursement of oncology treatment and control of various institutions on spending.
\end{abstract}

Key words: pharmacotherapy cost, oncologic diseases, cancer, treatment

Corresponding author: Assoc. Prof. Dr. Albena Zlatareva, MD, PhD, Medical University - Varna, e-mail: Albena.Zlatareva@mu-varna.bg

\section{INTRODUCTION}

A t present, cancer is a reason for $12 \%$ of all deaths by causes in the world [1]. It is expected to increase the number of deaths from 6 million to 10 million over the next 20 years. Around 20 million people in the world are living with the diagnosis of cancer as their number is expected to reach 30 million by 2020 [11].

Regardless of the global concern, indicators of morbidity and mortality showed at least two-fold differences between the European countries, they are more pronounced in specific locations of cancer. The effect of cancer has certain characteristics and even changes. These changes relate to the cancers, and for a given age group, gender and region. Observed differences in morbidity and mortality are also due to the different approach, measures and control in respect of various factors - exogenous and endogenous, leading to the occurrence of cancer diseases.
They have to comply fully with the demographic processes of population aging globally and its growth, which will lead to an annual increase in the number of patients with cancer over the next 15 years. In the greatest extent, these developments will affect the incidence of the most common cancers, which must be consistent with united action to control them [1].

Cancers historically, but also in personal one, are accepted as devastating and deadly diseases affecting almost all ages, along with a wide range of diagnostic and therapeutic methods. Investments by the pharmaceutical industry and the governments of different countries, especially members of the EU and the USA have multiplied in recent years [12].

According to the American Institute for the study of cancer diseases (AICR), oncology medicines cost USD 895 billion annually, more than any other group of diseases, for example: for cardiovascular disease are spent globally USD 753 billion, for road traffic accidents and diabetes - about USD 204 billion for each 
separately [13]. Price for a year of human life is increased from USD 139,100 in 2005 to USD 207,000 in 2013. The biggest financial impact in terms of point of loss of life and productivity occupy oncological diseases, accounting for $1.5 \%$ of the global gross domestic product (GDP). According to AICR $11 \%$ of these costs are for drug therapy. In 2015 National Bureau for Research and Economic Studies of the USA found that the prices of drugs "cancer" increased by $10 \%$ per year between 1995 and 2013.

In 2014, a study [17], published in The Lancet found that early treatment with drugs for oncological diseases is often impossible in low-income countries [17]. According to the American Cancer Society (ACS), the factors that determine the oncological treatment are the type of treatment, its duration, the place where it is held and the type of insurance coverage. Therefore, studies of the changes in the cost of oncology pharmacotherapy are necessary to reveal the tendencies and improve peoples' access to them.

Health insurance patients are the most important factor in the equation of personal health care costs of cancer patients. Insurance plans typically cover the major costs such as hospital stays, tests and procedures, and therapy prescribed by the attending physician. However, the study claimed there is no full coverage and full treatment of the sick and often require some type of additional payment [13].

The goal of this study is to analyze the cost paid by the public funds for oncology medicines in Bulgaria during 2013-2015 and to compare them with the cost in other EU countries.

\section{MATERIAL AND METHODS}

It was made literature search in the databases PubMed, Scopus and Google Scholar for the publications that cover the cost of oncology medicines, cost of oncology diseases and the way of their funding in the EU countries. The relevant studies that publish information about the total costs paid by public funds for oncology medicines are included in the analysis.

Then it was collected officially published information about the cost per INN (International Nonproprietary Names) paid for oncology medicines by the National Health Insurance Fund in Bulgaria during 2013-2015 in local currency. The exchange rate was EUR $1=$ BGN 1,958.

The changes in the cost were analyzed by calculating the percentage of increase (or decrease) by INN. Changes in cost were tested for statistical significance.

\section{RESULTS}

Costs on macro level for cancer patients in member states of the EU

Authors involved with the topic found that of all tested member states - Belgium, England, Estonia, France, Lithuania, the Netherlands, Northern Ireland, Norway and Poland - only four countries (Belgium, England, France and Poland) have estimated the total budget allocation for the implementation of activities, related to the therapy of oncological diseases. In Belgium, EUR 380 million were allocated between 2008 and 2010 for oncology diseases, in England GBP 70 million is allocated to "care cancer patients" every year, and in France 640 million euros have been allocated for cancer care in 2007, in Poland - three million Polish Zloty was allocated for the implementation of a program for cancer in 2006-2015 [14].

Eight of nine countries (except the Netherlands) have made clear statements about the need for additional funding to support the fight against "cancer". In the Netherlands, the authors noted that the new projects are funded by the redistribution of existing financial resources. Researchers, however, noted that the general lack of budgeting for projects for the treatment of cancer in many countries is alarming. The current financial climate exacerbates this problem, including rising levels of unemployment and rising government deficits [14].

Funding therapy for cancer treatment at the level of national programs in the EU

Authors working in the field investigated 14 members of the EU. In England, the average cost for oncology medicines increased to $60-80$ million pounds annually in recent years. In Italy investing in drugs is determined by analysis of costs and benefits, especially in terms of highly expensive innovative medicines [14].

Numerous researchers explored the specific reasons for the increasing costs of therapy of oncological diseases [15]. In the first place, these are high cost and long period of conducting clinical trials from phase 1 to phase 4; secondly, because most cancers are incurable, patients are treated with each approved agent (sequentially or in combination). This creates a virtual monopoly as the use of one drug does not automatically mean that the others are no longer needed. Third, even when the monopoly is broken by the arrival of "new and improved" versions of the approved drugs, the older (in the cases the most generic) drugs tends to be regarded as already unsuitable for therapy, thereby actually the cost even increases because the price of new, innovative medicines, and "monopoly of new drugs" remains. Fourth, the very 
nature of cancer diseases and severity of diagnosis play a role in patients and physicians who often are willing to pay the high cost of treatment even for minor improvements in outcome. Finally, the authors note that agencies such as the FDA, and EMA(European Medicines Agency), approving and authorizing the use of new products, as well as national councils makers for reimbursement of appropriate drugs, especially based on HTA (health technology assessment), cannot take their decisions solely on the basis of economic efficiency, without noting even psychological efficiency [16].

\section{Reimbursement approach in Bulgaria}

The National Health Strategy for the period 20082013 by Strategic Objective I: Ensuring conditions for health promotion and disease prevention provided in section 4.2 Development and implementation of programs for socially significant diseases and health problems representing national priorities (incl. Oncology diseases).

According to the National Framework Agreement between the National Health Insurance Fund and the Bulgarian Physicians' Union and the Union of Dentists in Bulgaria, cancer is included in the group of socially and priority for the country diseases [3].

There is a national strategy for prophylactic cancer screening (including cervical cancer), the schedules work program for the period 2001-2006 [4]. In the opinion of many experts, this program is not carried out according to its vision.

In December 2007, the 40th National Assembly established group "Parliamentary consensus on combating major diseases". The group is taking a number of actions and initiatives held a series of meetings and roundtables for the identification and possible solutions to major problems in the field of oncological diseases with the participation of leading experts in this field, including national and Republican consultants, non-government organizations and patient organizations, representatives of Presidency, Council of Ministers and the National Health Insurance Fund [4].

On June 12th, 2008, 40th National Assembly of the Republic of Bulgaria adopted unanimously statement in support of actions to limit and control of oncological diseases in Bulgaria. In pursuance of the Declaration of the National Assembly a working group to develop a national anti-cancer program and the National anticancer plan was set. In this connection it is prepared a National Program for Prevention and Control of Cancer in Bulgaria 2009-2018 and Plan for strategy, prevention and control of cancer in the Republic of
Bulgaria for the period 2009-2018 [6, 7]. The two documents are not validated. Therefore, the leadership of the Ministry of Health decided at that time a working group with the participation of patients' organizations to draw up to a national program to fight cancer in the Republic of Bulgaria up to February 15, 2010, then it should be presented to the Council of Ministers.

Currently, there is no functioning national program to fight cancer. Against this background, the measures to reduce the cost of cancer drugs are sporadic and unsystematic [10]. The amendments to Regulation 40, effective from 1 January 2014 [8], introduce the restriction that the innovative oncology products have to be included in the PDL (Positive List of Drugs) annually, thereafter, NHIF( National Health Insurance Fund) pays oncology products for the oral treatment not only in Annex 1 to the PDL but also in Annex 2 outside clinical paths even in recent years - 2014, 2015. In 2016 it is negotiated a separate sum of oncology products in the context of the total amount contained in a contract between the NHIF and the Medical Association

Evidenced by the report of NHIF from June 2015 to the ongoing implementation of the budget of the NHIF for medicines, the expected shortfall at the end of 2015 for drugs, medical devices and foods for special dietary purposes is going to be BGN 67468000 and for medicines to treat cancer in terms of hospital care BGN 54469 000. Such forecasts are made based on the rising average monthly expenditure in 2015 [9].

Although widely proclaimed measures to reduce the cost of drugs, including for cancer, the upward trend remained in each subsequent year (Table 1).

\section{DISCUSSION}

According to the international statistics on morbidity and mortality, the cancer frequency increases. In particular, in Bulgaria in 2013 (the latest published data) 10 neoplasms are the second leading causes of mortality 251.5 per hundred thousand population as male mortality remains much higher than in women. The incidence of malignant neoplasms also tends to increase [10].

In 2013, the incidence of malignant neoplasms increased compared to the previous year to 461.9 per hundred thousand inhabitants. These data indicate that regardless of the continually rising costs for the therapy of these disorders, yet those costs do not lead to effective results, both in terms of incidence, where the main factor is the prevention and in terms of reducing the death rate from cancer $[1,10]$. 


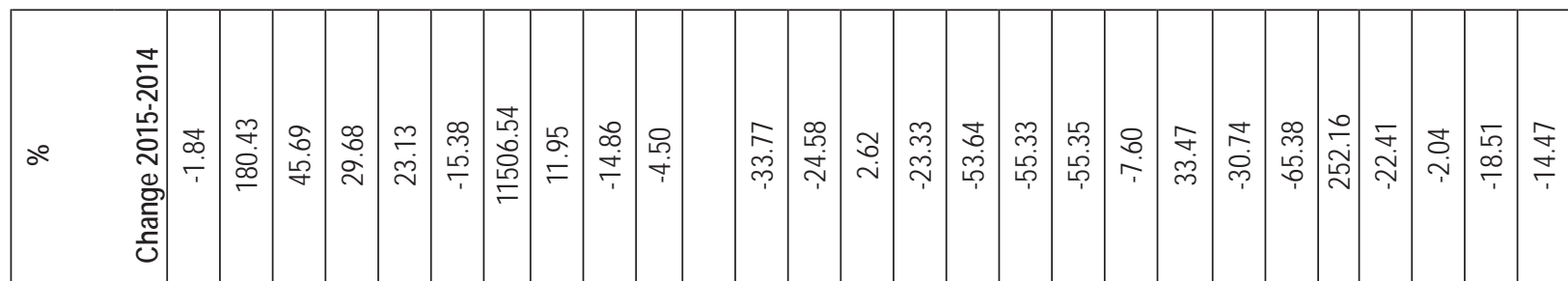
言

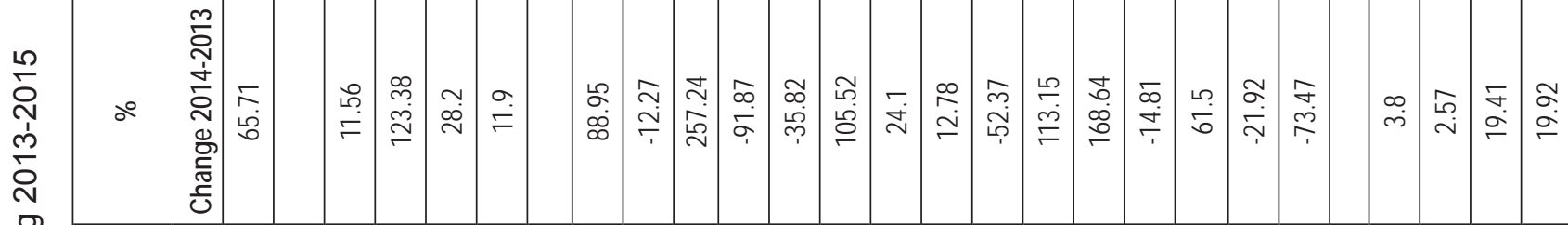
$\stackrel{\text { D }}{\stackrel{D}{5}}$

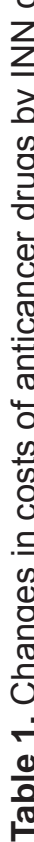

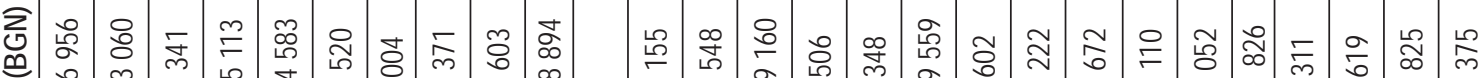

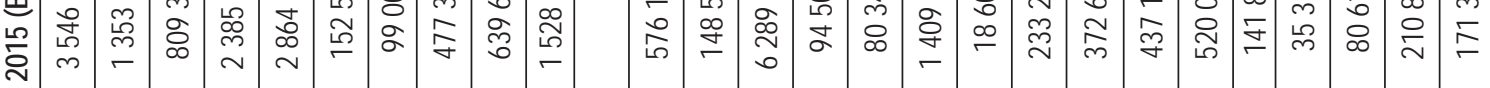

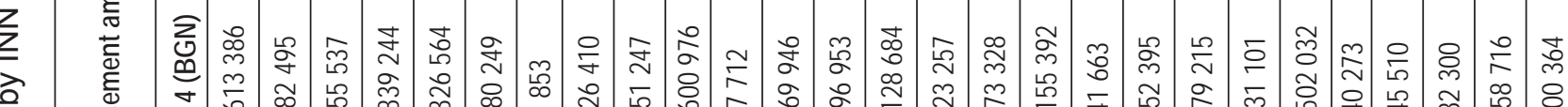

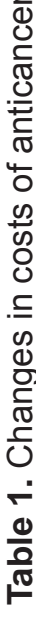

를

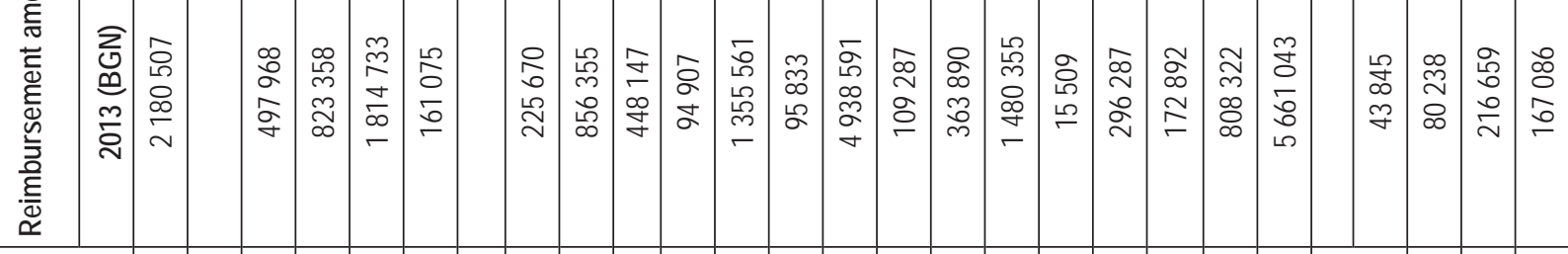

$\geq$ 落

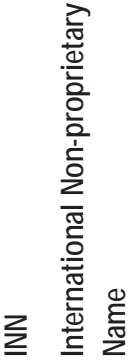

듬

言辛

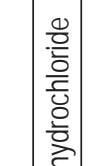

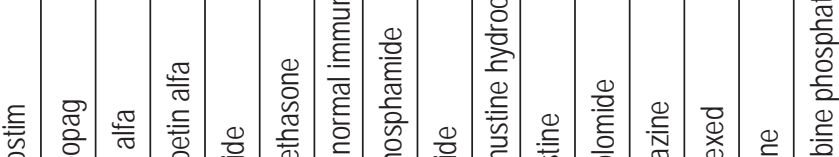

军

$\overline{\bar{\pi}}$

(1)

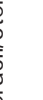

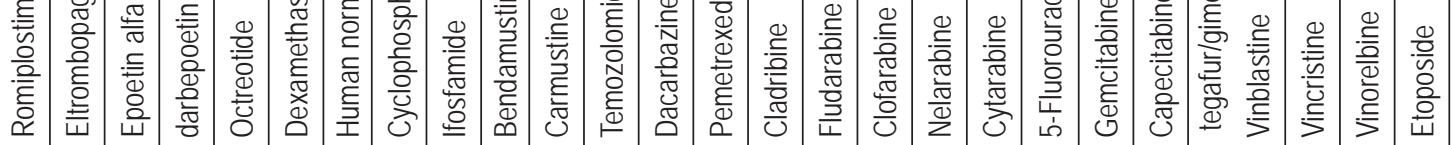

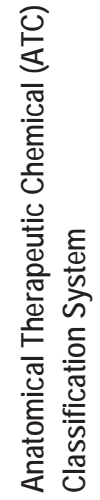

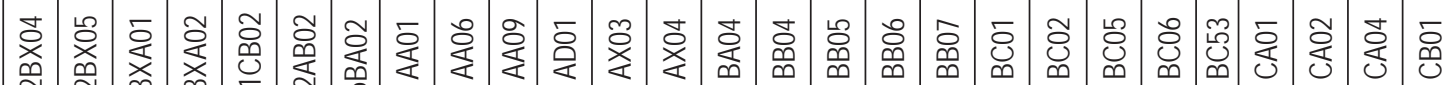

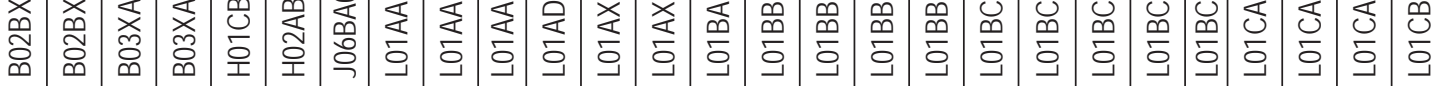




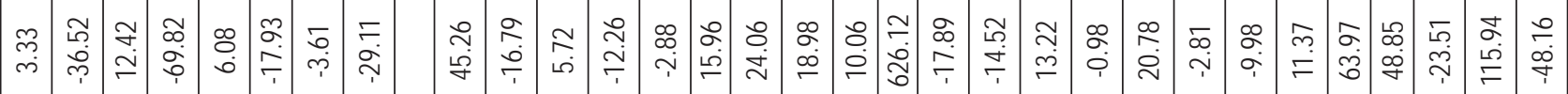

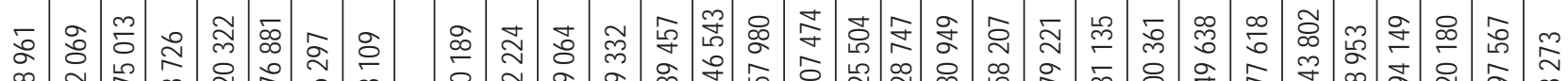

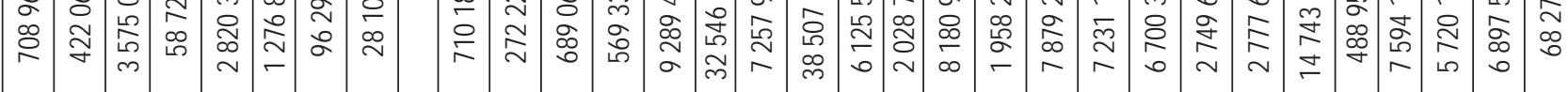

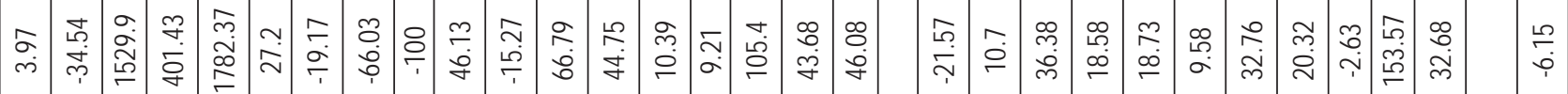

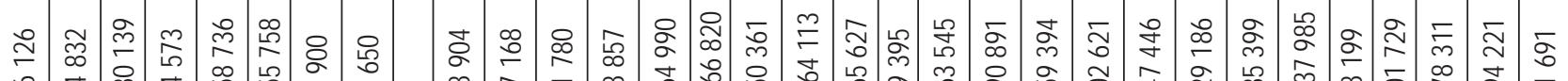

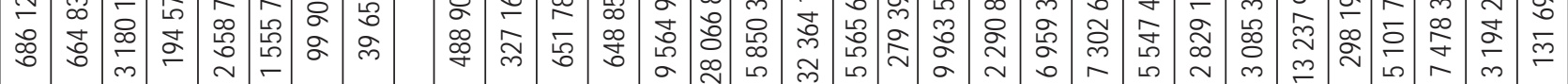

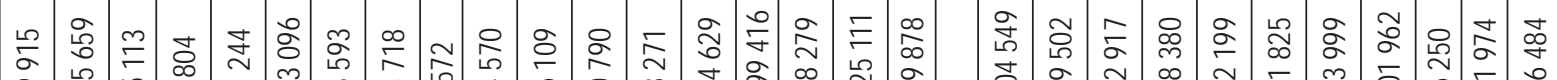

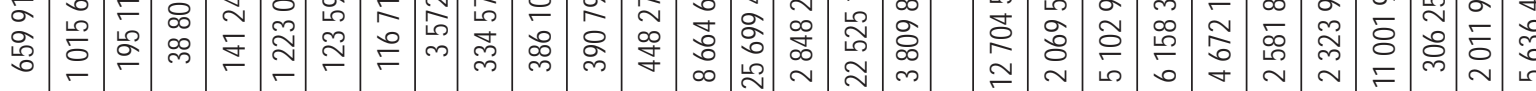

స్ల

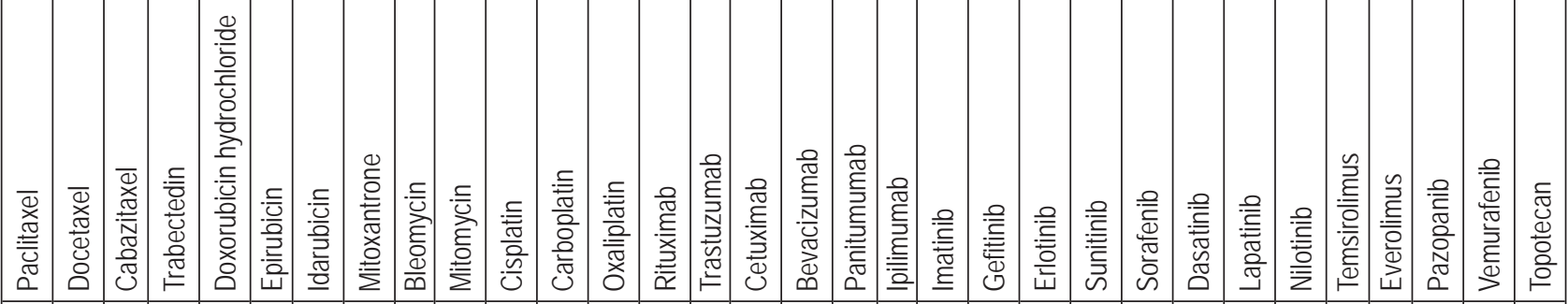

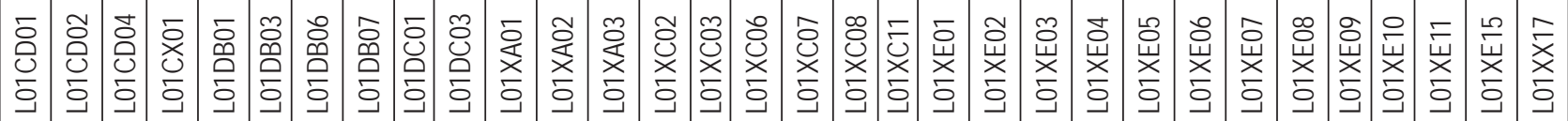




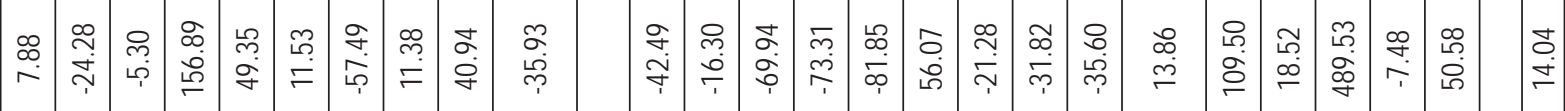

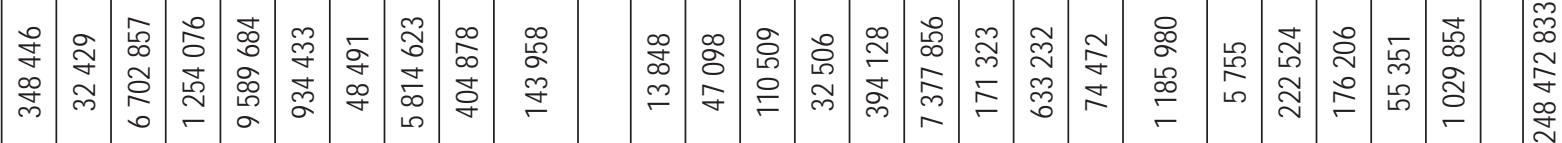

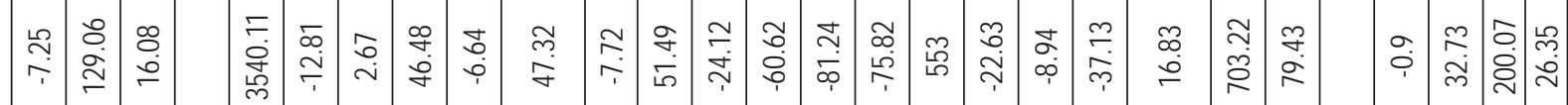

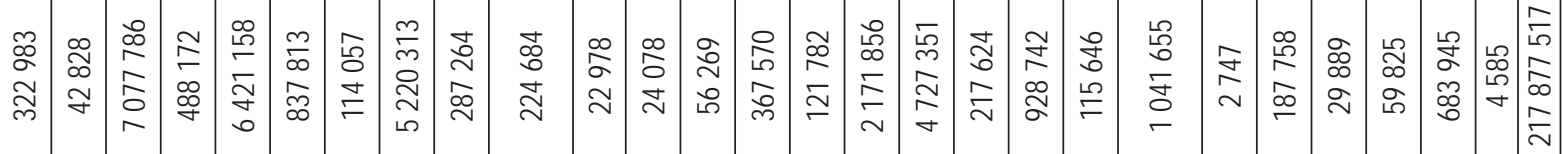

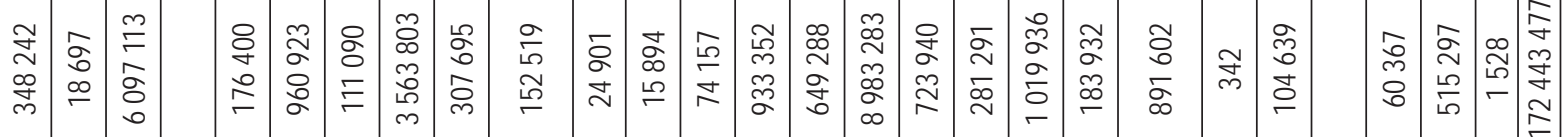

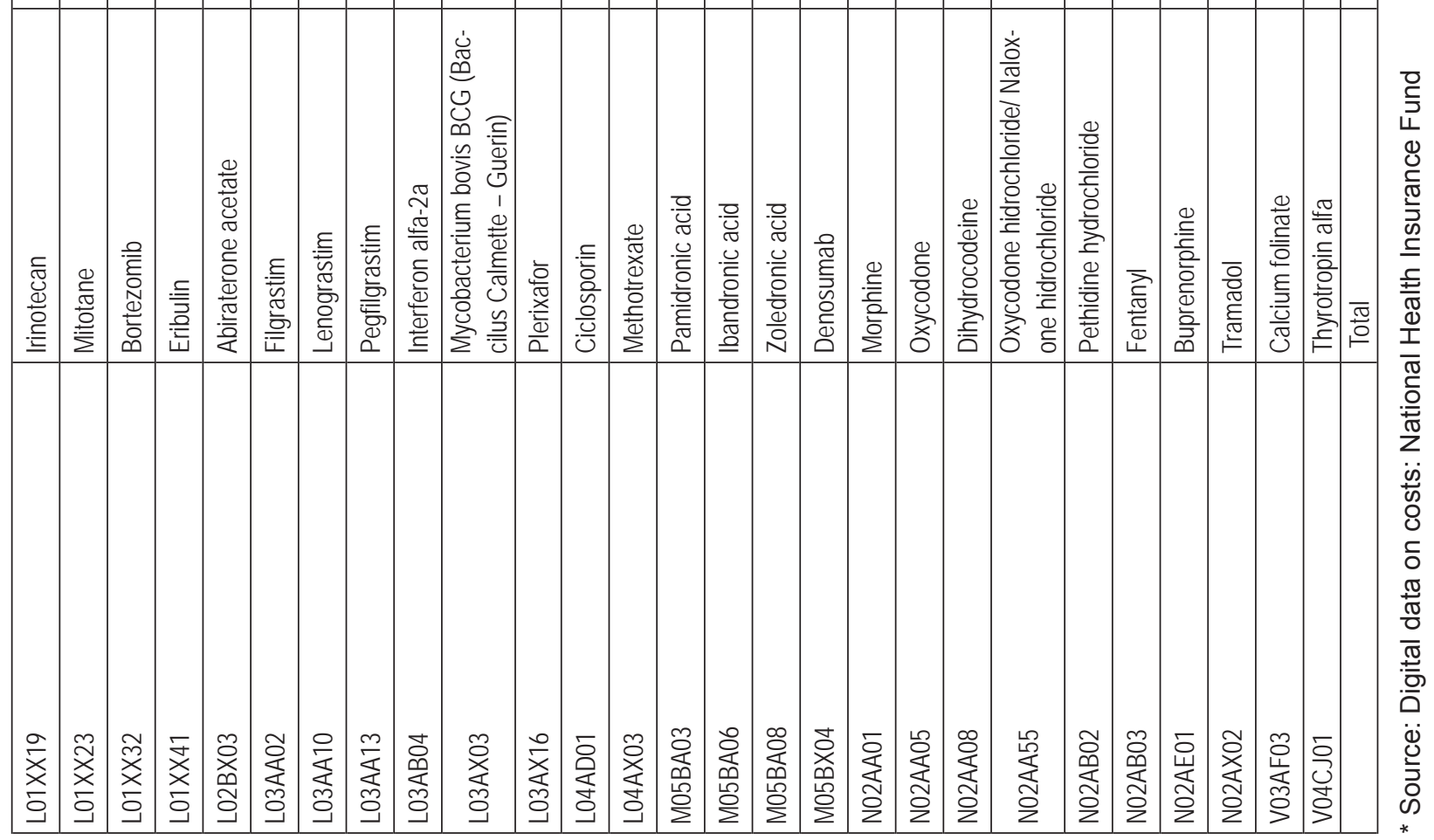


Table 2. Descriptive statistics of oncotherapy costs 2013-2014

\begin{tabular}{|l|l|l|l|l|l|}
\hline $\mathbf{N}=\mathbf{8 0}$ & Mean (SD) & Median & Mode & $\begin{array}{l}\text { Standard } \\
\text { error }\end{array}$ & Min/Max \\
\hline $\begin{array}{l}\text { Oncotherapy } \\
\text { costs }\end{array}$ & $\begin{array}{l}126.25 \\
( \pm 478.23)\end{array}$ & 17.70 & -100.0 & 53.56 & $\begin{array}{l}-100.00 \\
/ 3540.11\end{array}$ \\
\hline
\end{tabular}

Table 2 illustrates these statistical data for the period 2013-2014 in Table 1 and includes arithmetic average, minimum and maximum ones, standard error and standard deviation. It is important to know that information distribution is not normal, because the statistical dimensions such as notions have different values on a large scale. This is visible below in Histogram (Figure 1). This is not a problem for the analysis

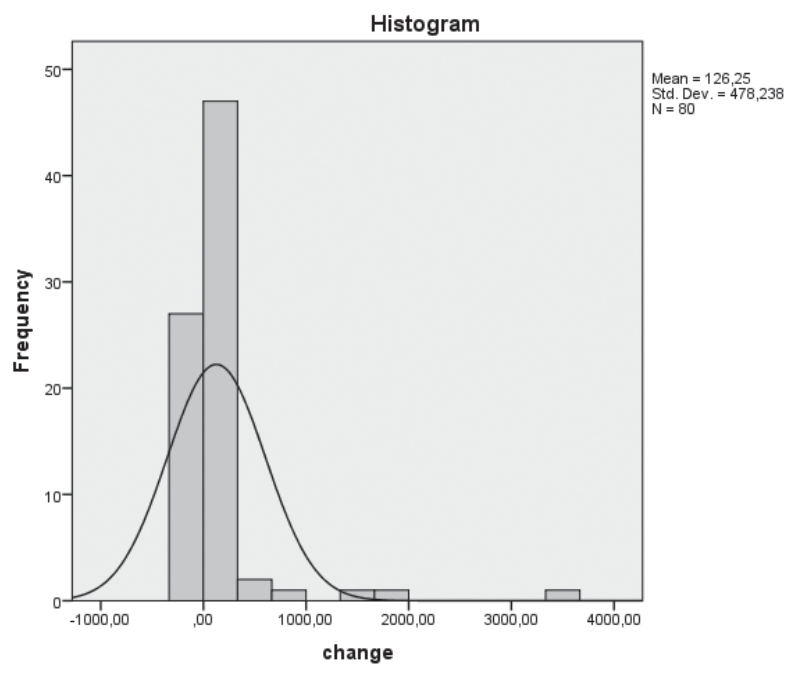

Fig. 1. Frequency distribution of the costs of oncotherapy of NHIF 2013-2014 - Change

All exported data here provoke several important questions: The National Cancer Registry publishes information on morbidity and mortality with a delay of at least two years of data.

There are no patient registries of the patients with cancer. The lack of such a database determines the impossibility of real forecast budget for medicines for treating of cancer diseases.

Last but not least, it is the question of the adequacy of control by the Public Fund on spending of cancer drugs and the increased in recent years parallel exports of such drugs [18].

It should be noted, however, the mere fact that access of Bulgarian patients to new, innovative drugs for the treatment of cancer is improved, although it is because the Figure 1 only shows the distribution of information according to their frequency. (Conclusions will apply to the sample, but cannot summarize cases beyond. When dealing with cancer diseases or extracts from non-randomized patients as well in this case, such graphics are possible.)

In a similar way, the descriptions of Figure 2 and Table 3 are following.

Table 3. Descriptive statistics of the costs of oncotherapy of NHIF 2014-2015

\begin{tabular}{|l|l|l|l|l|l|}
\hline $\mathbf{N}=\mathbf{8 2}$ & Mean (SD) & Median & Mode & $\begin{array}{l}\text { Standard } \\
\text { error }\end{array}$ & Min/Max \\
\hline $\begin{array}{l}\text { Oncotherapy } \\
\text { costs }\end{array}$ & $\begin{array}{l}157.19 \\
( \pm 1272.86)\end{array}$ & -2.845 & -81.85 & 140.56 & $\begin{array}{l}-81.85 \\
/ 11506.54\end{array}$ \\
\hline
\end{tabular}

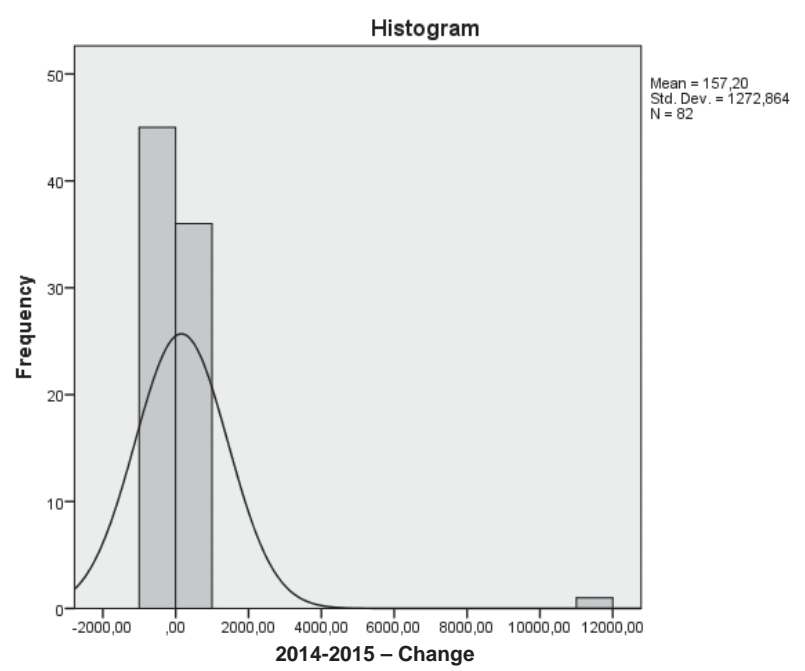

Fig. 2. Frequency distribution of the costs of oncotherapy of NHIF 2014-2015 - Change

once a year, subject to the regulatory framework [8], these new products are included in the PLD and are reimbursed by the NHIF.

\section{CONCLUSION}

These data showed that the cost of oncotherapy in Bulgaria followed the global upward trend, but the percentage on an annual basis is higher than average for developed countries.

According to these data, the progressive trend of the cost of almost all surveyed INN remains.

The reasons are probably due to better prevention and diagnosis, but in a relatively fixed number of patients an extremely high rate of change in the di- 
rection of increasing costs of the oncotherapy in our country is seen.

Specifying the actual causes requires control and analysis of specialized hospitals for oncology therapy, which number has also risen in recent years, particularly in the larger and more economically developed cities, as well as the effectiveness of the schemes and dosage regimens of oncology drugs.

\section{REFERENCES}

1. Bulgarian National Cancer Registry, the incidence of cancer, 2013, http://www.sbaloncology.bg/bg/patients/cancer-info/ statistics-pt.html

2. National Health Strategy 2008-2013, Council of Ministers, http://www.sbaloncology.bg/bg/patients/cancer-info/statisticspt.html

3. National Programme for primary prevention of cervical cancer in the Republic of Bulgaria, the 2012 -2016, http://www. mh.government.bg/bg/politiki/programi/aktualni-programi/

4. National strategy for prophylactic cancer screening, http:// www.mh.government.bg/bg/novini/aktualno/ministerstvotona-zdraveopazvaneto-osiguriava-100-/

5. Declaration of the National Assembly of the Republic of Bulgaria to restrict and control of oncological diseases in Bulgaria, www.parliament.bg /.../ 164Declaration\% 20NC\% 20za\% 20onkologichni\% ...

6. National Programme for Prevention and Control of Cancer in Bulgaria 2009-2018 .http: //www.parliament.bg/bg/plenaryst/ $\mathrm{ns} / 7 / \mathrm{ID} / 660$

7. Plan strategy, prevention and control of cancer in the Republic of Bulgaria from 2009 to 2018, the EU and the priorities of Bulgaria, www.ced.bg/uploads/project/EU\%202020.doc
8. Ordinance № 40 of 24.11.2004 laying down the basic package of health services guaranteed by the NHIF budget, www. nsoplb.com/uploads/docs/nar_40_112014.rtf

9. Report for the ongoing implementation of the Law on Budget of NHIF 30.06.2015, www.parliament.bg /.../ 201512101131200tchet\% 20NZOK\% 20\% 2030.0 ...

10. NSI, Health, 2014,http://www.nsi.bg/sites/default/files/files/ publications/Zdrave2014.pdf)

11. WHO, Access to new medicines in Europe: technical review of policy initiatives and opportunities for collaboration and researchhttp://apps.who.int/medicinedocs/documents/ s21793en/s21793en.pdf

12. Craig K. Deligdish. Cancer: Exploding Treatment and Diagnostic Pipeline, and Ever-Increasing Costs, http://www.ncbi. nlm.nih.gov/pmc/articles/PMC4046472,

13. Chris Elkins, How Much Cancer Costs,http://www.drugwatch. com/2015/10/07/cost-of-cancer/

14. Atun R, Analysis of National Cancer Control Programmes in Europettps://spiral.imperial.ac.uk/bitstream/10044/1/4204/1/ Cancer\%20Control\%20vf2.pdf

15. Mustaqeem Siddiqui,S. Vincent Rajkumar,The High Cost of Cancer Drugs and What We Can Do About It,http://www.ncbi. nlm.nih.gov/pmc/articles/PMC3538397/

16. McKee A.E., Farrell A.T., Pazdur R., Woodcock J. The role of the U.S. Food and Drug Administration review process: clinical trial endpoints in oncology. Oncologist. 2010;15 (suppl 1):13-18.

17. Spiegel $P$, Khalifa A, Mateen FJ. Cancer in refugees in Jordan and Syria between 2009 and 2012: Challenges and the way forward in humanitarian emergencies. Lancet Oncol 15:e290e297, 2014.

18. Scholz F, Schulte H-W, Weißenfeldt F. IMS Health, Parallel trade: Which factors determine the flow of goods in Europe? www.imshealth.de, 2015. 